\title{
Increased Expression of Bax and Bcl2 Apoptosis Biomarkers in the Heart of Old Female Rats after Interval Training and Curcumin Consumption
}

\author{
Bahareh Yazdanparast Chaharmahali ${ }^{1}$, Mohammad Ali Azarbayjani ${ }^{1 *}$, Maghsood Peeri ${ }^{1}$, Parvin \\ Farzanegi Arkhazloo ${ }^{2}$
}

1. Islamic Azad University, Central Tehran Branch, Physical Education Faculty, Tehran, Iran

2. Islamic Azad University, Sari Branch, Physical Education Faculty, Sari, Iran.

Article Type:

Original Article

\section{Article History:}

Received: 8 Dec. 2017

Revised: 27 May. 2018

Accepted:27 Jun. 2018

*Correspondence:

Mohammad Ali

Azarbayjani

Professor of Sport

Physiology, Islamic

Azad University,

Central Tehran

Branch, Physical

Education Faculty,

Tehran, Iran.

Email:

m_azarbayjani@iauctb.

ac.ir

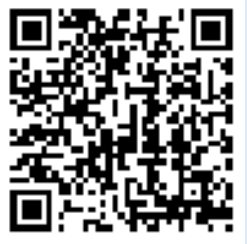

\begin{abstract}
Background and objectives: Elderly is characterized by decreased cardiac function, which is widely associated with mitochondrial failure in cell death. Elderly causes heart apoptosis. Although the old heart is vulnerable to apoptosis, physical training and some supplements through different mechanisms could be effective in reducing apoptosis. The present study aimed to investigate the effect of interval training on some apoptotic parameters of Bax and Bcl2 cardiomyocytes in old female rats.
\end{abstract}

Methods: In an experimental study, 49 Wistar female rats (2 years old) were randomly assigned into 7 groups: control, saline, curcumin, moderate intensity training, moderate intensity training + curcumin, high intensity training, high intensity training + curcumin. The experimental groups received gavage doses of curcumin $30 \mathrm{mg} / \mathrm{kg}$ body weight three days a week via. The saline group also received the same amount of saline. Training groups had moderate and severe exercises on the treadmill for eight weeks, and three sessions per week. Forty-eight hours after the last training session and gavage, the animals were killed and their heart tissues were isolated to determine the levels of Bax and $\mathrm{Bcl} 2$.

Results: The results indicated that interval training and curcumin consumption could significantly increase the levels of $\mathrm{Bcl} 2$ and $\mathrm{BAX}$ and the $\mathrm{BAX} / \mathrm{Bcl} 2$ ratio, the amount of which depends on the intensity of training. Moreover, the combination of training and curcumin had an antagonistic effect.

Conclusion: According to the results, physical activity and curcumin separately have a protective effect on the heart tissue; however, these two interventions do not enhance each other's effect. Hence each one is suggested to be used separately.

Keywords: Apoptosis; Interval training; Rat; Curcumin; Heart

\section{Introduction}

Elderly is described as a decrease in general physiological function (1). Gradual changes in the functions of a living creature ultimately lead to his death. Elderly is characterized by a decrease in cardiac function, including impulse volume, cardiac outflow, blood flow, oxygen uptake, and increased readiness for inflammation, oxidative stress, and diseases. With no heart functioning, inflammatory cytokines increase, and increased oxidative

Copyright $\odot$ 2018, Jorjani Biomedicine Journal has published this work as an open access article under the terms of the Creative Commons Attribution License (http://creativecommons.org/licenses/by-nc/4.0/) which permits noncommercial uses of the work while it is properly cited. 
stress is associated with both aging and cardiovascular diseases (1). Nowadays, it is believed that a significant reduction in the number of cardiac cells indirectly contributes to the reduction of contractile activity, heart tissue disease, heart diseases, and heart failure (1).

Losing heart cells occur with aging due to necrosis or apoptosis, both of which result in cell death. Apoptosis is a planned cell death characterized by no damage and inflammation but by shrinkage and collapse of the cell nucleus (1). In humans, apoptosis is in charge of maintaining the balance between cell proliferation and cell death, as well as fixing the number of cells in the tissues (34). Apoptosis plays an essential role in controlling the development, growth and replacement of cells. Although excessive apoptosis has been reported in diseases and heart failure, an increase in the apoptosis rate caused by aging is also observed in the left ventricle of mice. The progression of agerelated apoptosis in tissues like the heart is horrible because the lost cells are not replaced. Unfortunately, the mechanisms responsible for apoptosis and its signaling pathway in the old heart are still limited and unknown (1).

Studies have indicated that aging is associated with an increase in the BAX protein and an increase in the collapse of DNA in the brain $(4,7)$. The expression of $\mathrm{BAX}$ and $\mathrm{Bcl} 2$ proteins is increased in the heart of old mice. Nitahara (1998) reported an increased apoptosis in age-dependent cardiac cells in mice without significant changes in agerelated $\mathrm{BAX}$ and $\mathrm{Bcl} 2$ levels (2).

In response to the apoptotic stimulus, a variety of internal and external signals regulates the expression of genes that control the onset of apoptosis. On the internal pathway, the genes express the proteins that trigger apoptosis (e.g., Bax) and proteins that prevent apoptosis (e.g., Bcl2), and this in the cells (death vs. survival) depends the expression of the genes $(1 \& 2)$.

$\mathrm{Bcl} 2$ is an important protein that prevents apoptosis and inhibits the release of cytochrome $\mathrm{C}$ from mitochondria. The high amount of Bcl2, compared to Bax, causes cell survival, while the opposite ratio makes the cell die (3).

Physical exercise is a key for physiological compatibility, with no alternative for heart and heart patients (4). In recent years, endurance sports have been identified as a protection against ischemia-reperfusion (I / $\mathrm{R}$ ), and this is one of the specific aspects of the endurance exercise mechanism for heart protection. In fact, recent findings explain that regular exercises protect the heart against apoptosis. Physical activity may significantly play a role in preventing apoptosis of I / Rinduced cardiac cells through increasing cardiac catalase activity, given that the activity of GPX, Mn SOD, and $\mathrm{Cu} / \mathrm{Zn}$ enhances due to high physical activity (5). Physical exercise has the potential to reduce apoptosis by protecting stress-sensitive proteins, including NF-KB, IGF-1, and HSP70. Kvack showed that the BAX / Bcl2 ratio is adjusted to age and is significantly reduced by exercises in the left ventricle (1). This information indicates that an elderly's heart is more susceptible to apoptosis than a younger's heart, and that physical exercises cause anti-apoptotic activity in the heart of the elderly. Recent studies have revealed that exercises reduce Bax and caspase expression and increases the expression of $\mathrm{Bcl} 2$, an antiapoptotic protein, in both healthy muscles and heart cells. A clinical study also indicated that training reduces muscle cell apoptosis over a 
long run and increases the antioxidant capacity in cardiac patients (6). Curcumin is a peppermint extract of Turmeric, used in Chinese herbal medicine. In recent years, many studies have been conducted on the curcumin effects, including its antiinflammatory, anti-oxidant, anti-infectious, anti-tumor, coronary artery anti-blockage, and coronary artery protection effects. Curcumin is prescribed as an effective cardiac protection medicine that protects the heart from high-fat ischemia and atherosclerosis. Studies have suggested that curcumin has anti-oxidative, anti-apoptotic and anti-inflammatory therapeutic properties (7). Curcumin has been used as an anti-apoptotic factor and its effects on mammalian heart cells have been confirmed $(6,8)$. Experiments have shown that curcumin causes cell survival by activating PI3K, AKT, and ERK1 / 2 and preventing JNK activity. It also increases the expression of the $\mathrm{Bcl} 2$ gene and prevents apoptosis and cell death. Studies have revealed that curcumin specifically controls the apoptosis pathway through increasing the Bax / Bcl2 ratio and inhibiting PI3K / AKT. Thus, curcumin prevents apoptosis by preventing the expression of NADPH oxidase and ERS protein (8). Some investigations have mentioned that curcumin improves physical activity and delayed fatigue (9). Research on the simultaneous effect of exercise activity and curcumin consumption on the heart and its function has indicated that curcumin and physical activity improve the function of the left ventricular (10) and vascular endothelial (11); however, the simultaneous effect of curcumin and physical activity on apoptosis in the heart has not been studied yet.

According to many studies, although physical activity is an effective intervention for preventing primary and secondary cardiovascular diseases, the nature, duration, and intensity of exercises useful for cardiovascular health are still unknown $(1,5$, and 10). Physical activity has a potential to moderate cell proliferation and death through cytokines, hormones, growth factors, and metabolic pathways. Recently, there is some evidence indicating apoptosis in lymphocytes and skeletal muscles caused by physical exercises (4). Physical exercises may have protective factors in reducing oxidative stress, mitochondrial dysfunction, and mitochondrial caspase apoptosis in the elderly. Studies have argued that physical activities may improve the function of the heart and prevent the blockage of veins $(12,13)$. However, the effect of training intensity and curcumin on cardiovascular health is rarely studied and further studies are required. This study aimed to examine the simultaneous effects of both training and curcumin consumption on the expression of some genes associated with early heart apoptosis in rats to positively contributes to the prevention of heart diseases and elderly healthcare cost reduction.

\section{Materials and Methods}

The statistical population of this study encompasses elderly female Wistar rats (2 years old) with a mean weight of 250-250 gr from the Research Center for Laboratory Animal Breeding in Azad University, Sari Branch. The animals tested in this study during the research phases were kept in transparent polycarbonate cages of $15 \times 15 \times$ $30 \mathrm{~cm}$, manufactured by Razi Rad Company, with a light to darkness cycle of 12:12 hours, an ambient temperature of $22 \pm 2{ }^{\circ} \mathrm{C}$, air humidity of $50 \pm 5 \%$, and appropriate ventilation. The mean and standard deviation of the rats' weights are presented in Table 1. The rats in this study were fed based on their weight every other three days using a special 
Table 1. Mean and standard deviation of rats' weights in grams. Data is reported in means \pm standard deviation.

\begin{tabular}{ll}
\hline Groups & Weight (gr.) \\
\hline Control & $1.4 \pm 255.52$ \\
\hline Saline & $56.17 \pm 268.44$ \\
\hline Curcumin & $27.63 \pm 243.67$ \\
\hline Moderate Intensity Training - Curcumin & $26.66 \pm 266.45$ \\
\hline Moderate Training & $27 \pm 265.38$ \\
\hline High Intensity Training - Curcumin & $33.66 \pm 264.39$ \\
\hline High Intensity Training & $32.87 \pm 264.41$ \\
\hline
\end{tabular}

During all stages of the study, the animal's required water was available to them. Out of them, 49 mice were selected and, after entering the experiment environment and getting acquainted with the conditions, they were randomly assigned to seven groups $(n=7$ per group): saline, curcumin, moderate intensity training + curcumin, moderate intensity exercise, high intensity training + curcumin, and high intensity training. The training group rats were trained for 5 minutes five days on a treadmill before starting the main training protocol. Then a training session was conducted to measure the maximum degree of exhaustion, with the mean of 28 meters per minute. The average interval training program lasted for 8 weeks (3 sessions per week), and each sessions contained 10 one-minute sets with $50 \%$ exhaustion intensity and a 2-minute break between the sets. The first week started with 14 meters per minute and 2 meters per minute was added to the speed per week, reaching 28 meters per minute in the eighth week. The high intensity interval training program was similar to the moderate intensity exercises, but with an intensity of $70 \%$ exhaustion, which started with $20 \mathrm{~m} / \mathrm{min}$ in the first week and was increased by $2 \mathrm{~m} / \mathrm{min}$ per week, reaching $34 \mathrm{~m} / \mathrm{s}$ in the eighth week. Also, five minutes before and after exercises were considered for warming up and cooling the animals. As a result, each training session lasted for 40 minutes during the study (35). The training protocol was performed by a fully automatic treadmill. The pure curcumin was purchased from Sigma Co. in Germany. The training and supplement groups received $30 \mathrm{mg}$ of curcumin per gram of body weight for 3 days a week as gavage. The saline group also received the same dose as gavage. Table 2 shows the intensity of exercise per week in experimental groups.

Eight weeks after the study, all animals under totally similar conditions followed by 12-14 hours fasting, 48 hours after the last session of training and gavage, were injected intraperitoneally with ketamine $(6 \mathrm{mg} / \mathrm{kg}$ of rats' weights) and Xylacin $(5 \mathrm{mg} / \mathrm{kg}$ of rats' weights) to be anesthetized. Then with after ensuring their full anesthesia using corneal 
reflux, their breasts were cut and cardiac tissues were separated.

Table 2. Intensity of training programs by weeks

\begin{tabular}{lll}
\hline Week & $\begin{array}{l}\text { Moderate intensity training (M / } \\
\text { min) }\end{array}$ & High intensity training (M / min) \\
\hline First & 14 & 20 \\
\hline Second & 16 & 22 \\
\hline Third & 18 & 26 \\
\hline Fourth & 20 & 28 \\
\hline Fifth & 22 & 30 \\
\hline Sixth & 24 & 32 \\
\hline Seventh & 26 & 34 \\
\hline Eighth & 28 & \\
\hline
\end{tabular}

\section{Quantitative analysis of gene expression}

RNA was extracted from the heart tissue using Qiazol (Germany Qiagen kit) according to the manufacturer's instructions. RNAasefree DNA-ase enzyme was used to eliminate the risk of RNA contamination with DNA. Required quantities were determined based on the concentration of the extracted RNA as $1 \mu 1$ of DNase Fermentase and $1 \mu$ of buffer 10X were added to $1 \mu \mathrm{g}$ of extracted RNA, and the volume of solution treated with DEPC and water reached $10 \mu \mathrm{L}$. The solution was placed at $65^{\circ} \mathrm{C}$ for 15 minutes to deactivate the enzyme. The concentration of RNA was determined by spectrophotometry (Germany UV Eppendroff). To produce cDNA, $1 \mu 1$ of oligo dt was added to $0.2-1 \mu \mathrm{g}$ of extracted RNA. The final volume at this step should be $12 \mu \mathrm{l}$; thus, if the RNA was more concentrated, it was less picked and treated with DEPC and water to reach the final volume of $12 \mu \mathrm{l}$. The reaction was placed at $70^{\circ} \mathrm{C}$ for 5 minutes and then immediately transferred to the ice. Then $4 \mu$ of buffer $5 X$, $2 \mu \mathrm{l}$ of dNTp, and $1 \mu \mathrm{l}$ of RNase were added to the microfuge, and the final volume was 19 $\mu 1$. The reaction solution was incubated at 37 ${ }^{\circ} \mathrm{C}$ for 5 minutes. After that, $1 \mu \mathrm{RT}$ enzyme was added to the reaction and incubated at 42 - $\mathrm{C}$ for 1 hour. To stop the reaction, the micro-tube was placed at $70{ }^{\circ} \mathrm{C}$ for 10 minutes. The CDNA was placed on the ice and was maintained at $20^{\circ} \mathrm{C}$ until the PCR reaction was performed. Primers were made by Sina Gene Company. The sequence of primers is presented in Table 3. In this study, GAPDH gene was used as an internal control. Each PCR reaction was performed using the PCR Master Mix Applied Biosystems, SYBR Green in the ABI STEP ONE DETECTION APPLIED BIOSYSTEMS, SEQUENCE CA SYSTEMS, and FOSTER CITY according to the manufacturer's protocol. Fourty cycles were considered for each REAL-TIME PCR cycle and the temperatures of each cycle were 94 degrees Celsius for 15 seconds and 60 
degrees Celsius for 30 seconds. Including the data in the $\Delta \Delta \mathrm{C} 1$ and $-2 \Delta \Delta \mathrm{C} 1$ formulas, the expression of the target gene was normalized by reference genes, and at each phase, the blastocyst gene expression of the control group was considered as a calibrator.

Table 3. Primer sequences

\begin{tabular}{cc}
\hline Bax R & CAG CCA CAA AGA TGG TCA \\
\hline Bax F & GCA AAC TGG TGC TCA AGG \\
\hline Bcl2 R & TTTTGCTGCTCACTGTATTTTATTTT \\
\hline Bcl2 F & ACTTTTAGGCGTGGCTGATG \\
\hline Casp3 R & GCACAAAGTGACTGGATGAAC \\
\hline Casp3 F & TGTATTCTTACTCTACCGCAC \\
\hline
\end{tabular}

\section{Data Analysis}

All statistical operations were performed using SPSS software version 22. Regarding the descriptive statistics, mean and standard deviations were used. In the inferential statistics section, the results were analyzed for independent groups using two-way analysis of variance. Bonferroni post hoc test was also employed in the case of significant differences to determine the exact position of difference between groups. The significance level was set to be $\mathrm{P} \leq 0.05$.

\section{Results}

In this study, all the rats completely had different trainings and curcumin consumption. The first finding showed that injection had no significant impact on the expression of caspase $3(p=0.282)$, BAX $(P=0.854)$ and Bcl2 $(\mathrm{p}=0.686)$. Training significantly increased the caspase 3 expression, in comparison to the control group $(\mathrm{P}=0.0001)$. The expression level of this gene was higher in the high intensity training group than moderate intensity training group $(\mathrm{P}=$
0.0001) and sham group $(\mathrm{P}=0.0001)$. Curcumin increased the caspase 3 expression, compared to the sham group $(\mathrm{P}=0.0001)$; however, the interaction of training and curcumin caused a significant decrease in caspase expression $(\mathrm{P}=0.0001)$. The simultaneous use of curcumin and training reduced the caspase 3 expression, which can be considered as an antagonistic effect associated with the intensity of training (Figure 1).

Training, especially high intensity training, significantly increased BAX expression $(\mathrm{P}=$ 0.003). Expression of this gene was higher in high intensity training group than in moderate intensity training group $(\mathrm{P}=0.0001)$ and sham group $(\mathrm{P}=0.0001)$. While curcumin significantly reduced the BAX expression compared to the sham group $(\mathrm{P}=0.0001)$, the interaction of training and curcumin had a significant effect on the BAX expression ( $\mathrm{P}=$ 0.0001) and decreased BAX expression. The decline was greater when combining moderate intensity training and curcumin (Fig. 2). 



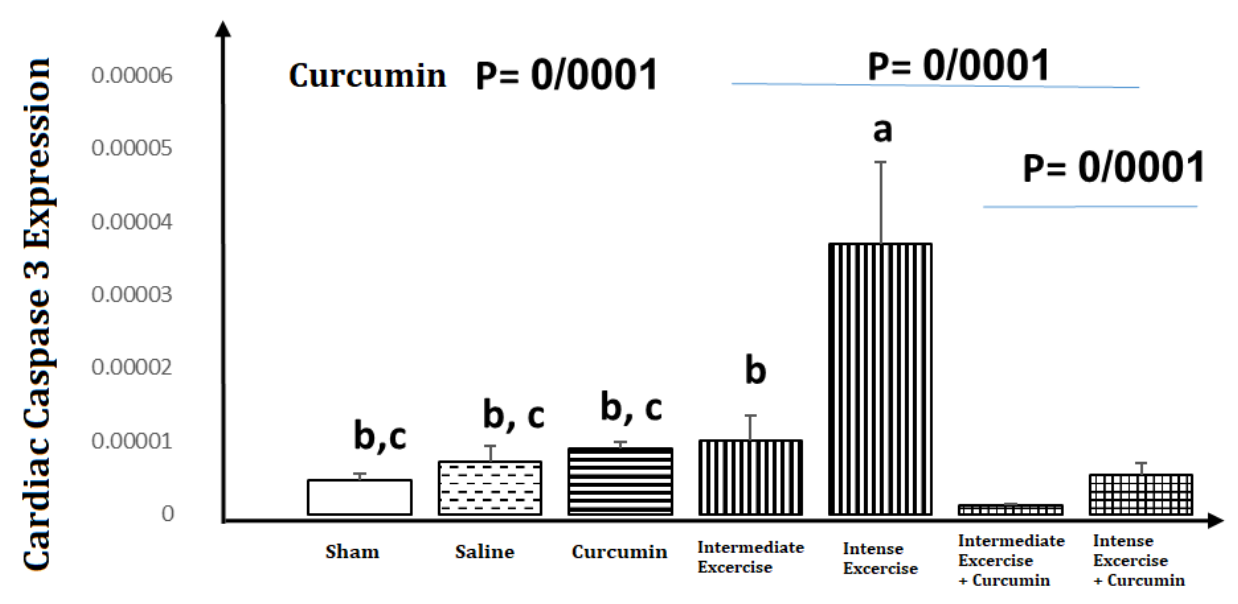

Figure 1. Cardiac caspase 3 expression in the study groups. Data is reported in means and standard deviations.

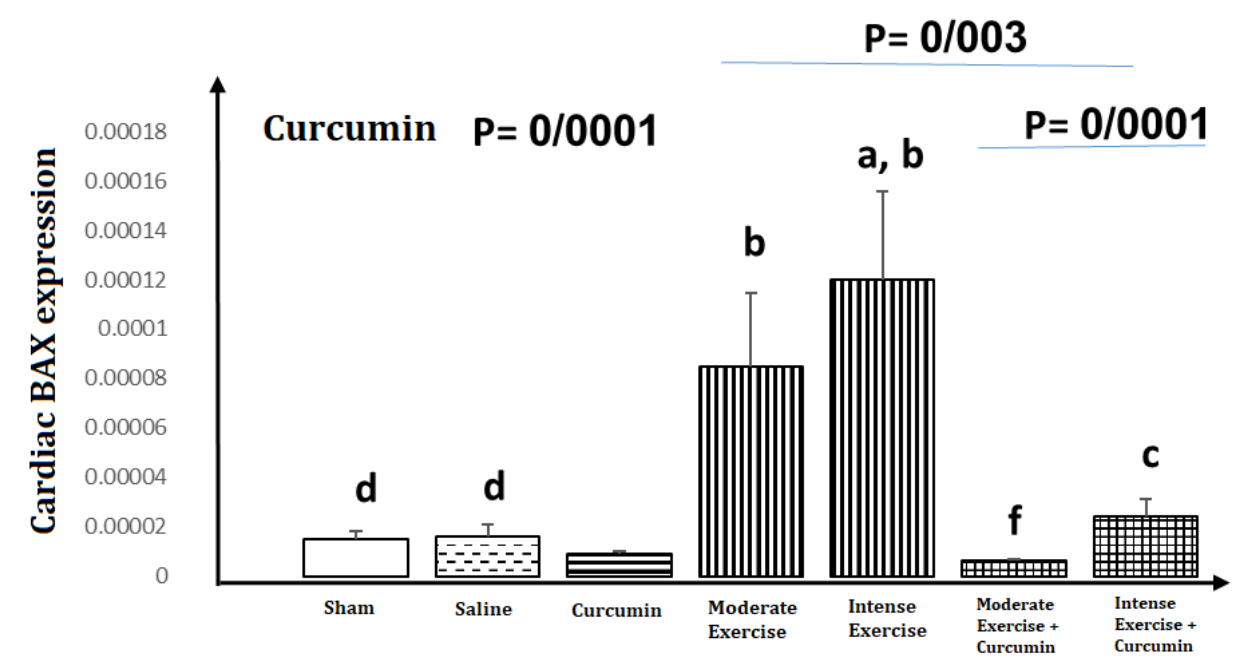

Figure 2. Cardiac BAX expression in the study groups. Data is reported in means and standard deviations.

Training increased the $\mathrm{Bcl} 2$ expression $(\mathrm{P}=$ 0.001), and such an increase was related to its intensity, so that the expression of this gene in the high intensity training group was higher than in the moderate intensity training group $(\mathrm{P}=0.0001)$ and sham group $\mathrm{P}=0.0001)$. Curcumin also significantly increased the
$\mathrm{Bcl} 2$ expression $(\mathrm{P}=0.0001)$. The interaction of training and curcumin reduced the $\mathrm{Bcl} 2$ expression $(\mathrm{P}=0.002)$, and this decrease was related to the intensity of training. The simultaneous use of curcumin and high intensity training more significantly reduced the Bcl2 expression (Fig. 3). 


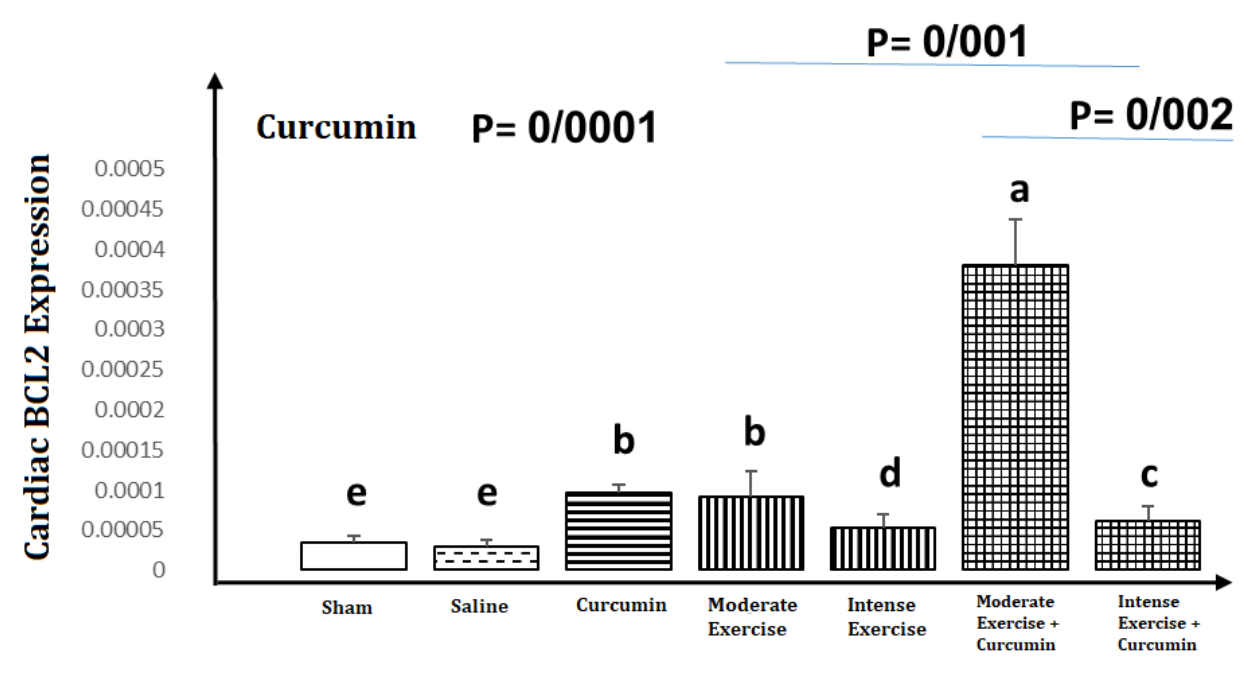

Figure 3. BCL-2 expression in the study groups. Data is reported in means and standard deviations.

Training significantly increased the BAX / $\mathrm{Bcl} 2$ ratio $(\mathrm{P}=0.05)$, which was higher in the high intensity training group than the moderate intensity $(\mathrm{P}=0.05)$ and sham $(\mathrm{P}=$ 0.05) groups. Curcumin also caused a significant increase in the expression of BAX $/ \mathrm{Bcl} 2$ ratio $(\mathrm{P}=0.006)$, compared to the sham group. The interaction of training and curcumin significantly decreased this ratio, while its value was greater in high intensity and curcumin group than in the moderate intensity and curcumin group (Fig. 4).

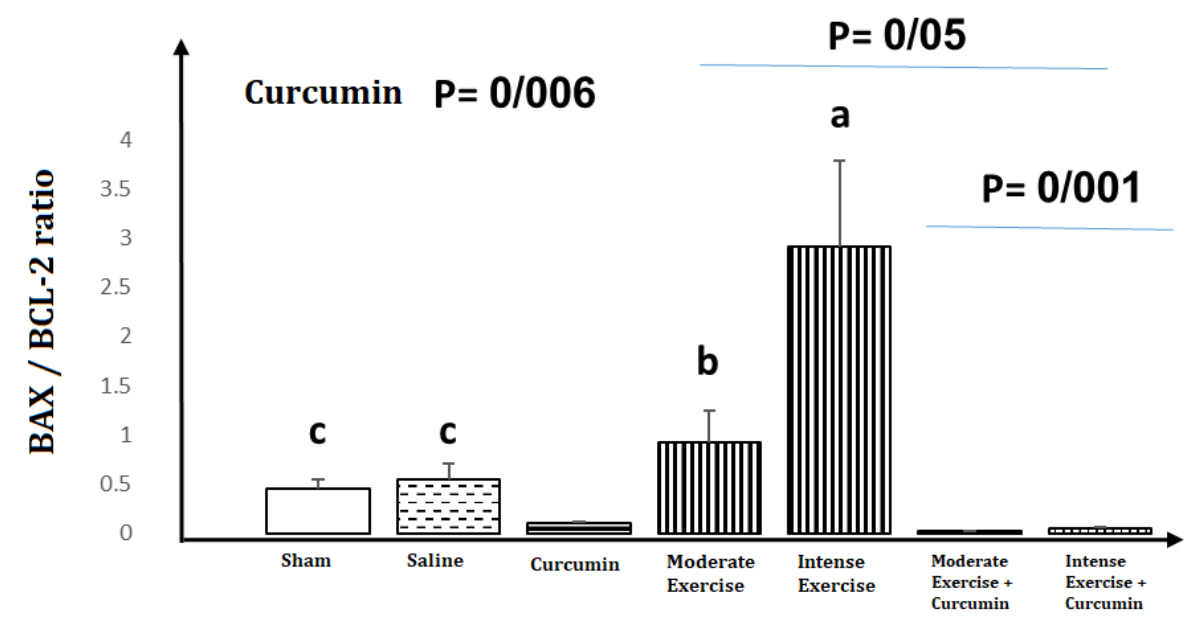

Figure 4. BAX / BCL-2 ratio in the study groups. Data is reported in means and standard deviations. 


\section{Discussion}

The results of this study showed that BAX and Caspase 3 apoptotic indices and $\mathrm{Bcl} 2$ antico-apoptotic index were expressed under the influence of interval training and curcumin consumption. The high intensity training increased the expression of $\mathrm{BAX}$, Caspase 3 and $\mathrm{BAX} / \mathrm{Bcl} 2$ ratios, and moderate intensity training reduced the expression of apoptosis indices and increased Bcl2 anti-apoptotic index.

With aging, the death of the heart cells also increases. Aging is a complex process that is associated with changes in the physiological, morphological, cardiovascular and extracellular matrix systems, all of which contribute to apoptosis and necrosis in cell death. A number of studies have reported that the expression of P16 / INK4A and P53 genes in the cells of the old heart tissues increases, and that the aging of the cell begins with the changes in the telomerase enzyme and leads to apoptosis $(10,14)$. A number of studies have also indicated that apoptosis occurs at an elderly age due to reduced activity of the Sarcoplasmic Reticulum ca ATPase enzyme and decreased expression of Bcl2 and Survivin (19). Caspase 3 is a key to apoptosis, which regulates this process on the cell apoptosis pathway. Bcl2 is necessary for the apoptosis process because it stops the cell death process. Moreover, the BAX gene is also recognized as the first member of the Bcl2 family, in line with apoptosis (16). In this study, expression of Bcl2 and BAX by curcumin showed a significant mechanism for the anti-apoptotic effect of curcumin. Hugging et al. documented that curcumin consumption reduced damages to heart cells through preventing apoptotic outflows in old mice. Curcumin and training reduced the $\mathrm{BAX} / \mathrm{Bcl} 2$ ratio, inhibited Caspase 3 activity, and prevented DNA collapse (16).
Curcumin causes the phosphorylation of JAK2 and SATAT3, which regulates the Bc12 / BAX ratio of the heart cells and inactivity of Caspase 3 (1).

The findings of this study showed that the anti-apoptotic effects of curcumin improve cardiac function and prevent heart damage. The study introduced a new mechanism for the prevention of cardiac damage by curcumin, which may contribute to the development of therapeutic benefits of this supplement in the case of limited function of cardiac cells and apoptosis (16).

Lee et al. (2013) reported that physical training as a new medication could prevent the apoptosis. Physical exercise prevents the activity of mitochondrial-dependent apoptosis, which is characterized by increased expression of $\mathrm{Bcl} 2$ and decreased $\mathrm{Bax}$ and BAX / Bcl2 ratio, decreased caspase 9 activity, and inactivated caspase 3 (17). Previous studies have reported that physical activity reduces the BAX expression, caspase 3 activity, and DNA collapse in the heart muscle; however, it causes no change in the skeletal muscle of obese mice (18). These findings confirmed that physical exercises protect the heart against apoptosis (17). Physical activity prevents apoptosis through the mitochondrial pathway. Bcl2 family proteins mediate the mitochondrial pathway of apoptosis, which prevent the release of cytochrome C from mitochondria (19). Increased BAX / BAK, ROS, and calcium ions releases the cytochrome $\mathrm{C}$ from mitochondria into cytosol. hence physical activity seems to be beneficial to some extent in preventing cardiac apoptosis through reducing the ROS and preventing the release of mitochondrial cytochrome C (19).

The effect of training on heart health in patients may be due to several factors such as reduced lipoprotein, strengthened heart 
muscle, improved antioxidant and antihypertensive capacity $(20,21)$; therefore, the therapeutic effects of physical activity on cardiomyopathic changes and cardiac apoptosis can be attributed to different factors such as weight loss, blood pressure changes, antioxidants, and other unknown factors (17). Progressive decline in heart muscle cells occurs in aging and heart failure, and both necrosis and apoptosis play an important role in this process. In addition, Kajestura et al. showed that apoptosis in the left ventricle of the 24-month-old mice were $200 \%$ more frequent than in the 16-month-old mice; however, necrotic cell death was not less observed. They strongly suggested that apoptosis may be more common in old mice than necrosis.

In the present study, moderate intensity treadmill training inhibited the BAX expression and increased the $\mathrm{Bcl} 2$ expression in old mice. Zhang et al. reported that low changes of the observed mitochondrial DNA in aging increase apoptosis in old mice. Phaneuf and Leonberg reported that BAX and $\mathrm{Bcl} 2$ played a critical role in aging mitochondrial apoptosis (22). The $\mathrm{Bcl} 2$ membrane prevents apoptosis through preventing the release of cytochrome $\mathrm{C}$ from mitochondria. Cell death is prevented by increasing the $\mathrm{Bcl} 2$ / $\mathrm{BAX}$ ratio, thereby reducing apoptosis by inhibiting the release of cytochrome $\mathrm{C}$ and activating caspase 3 (23).

Our study revealed that the $\mathrm{Bcl} 2$ expression is increased with curcumin consumption and moderate intensity training. Zhang suggested that a planned response is made to save the heart cells of the old mice (24). In their study, mitochondrial DNA mutation in the mouse' heart stimulated a safe response, which included high $\mathrm{Bcl} 2$ regulation. Both planned activities to save the cell and its death may occur in the heart of the old mice. The beneficial effect of physical activity on the myocardium in old mice was the prevention of Bax expression, and the increase of $\mathrm{Bcl} 2$; thus, regular training might be a useful strategy for the prevention of heart problems in the elderly (23).

Lee et al. (2000) reported that apoptoticdependent cardiac receptors in rats were less active after 12 weeks of physical activity, and the mitochondrial-dependent apoptotic pathway decreased significantly after 12 weeks of training, the anti-apoptosis $\mathrm{Bcl} 2$ increased, and $\mathrm{BAX}$ and $\mathrm{BAX} / \mathrm{Bcl} 2$ ratio decreased (17).

Cardiac apoptosis is an essential process that can alter the ventricular structure and lead to heart failure in response to many stimuli, such as hypoxemia (25), and is the goal of a therapeutic potential that occurs in the early stages of apoptosis. Jeng et al. (2016) found that curcumin resulted in a significant decrease in the size of the infructuous area of the mice and reduced the hypoxia that caused the apoptosis of the heart (26). Curcumin is a yellow polyphenol with therapeutic properties and has been used in traditional Chinese medicine for the treatment of many diseases (27). There are many evidence that curcumin has beneficial effects for cancer patients and patients with inflammation $(28,29)$. In recent years, the protective effects of curcumin on the cardiovascular system have been detected (30). Animal experiments show that curcumin prevents heart hypertrophy (31) and hypertension that causes fibrosis (32) and also prevents heart failure (31). In mice with myocardial attack, researchers found that curcumin induced cardiac rehab and improved cardiac failure after heart attacks (33).

Endurance exercises are reported to cause downward regulation of caspase and BAX and an upward adjustment of $\mathrm{Bcl} 2$ in both skeletal and cardiac muscles in mice (6). These anti-apoptotic effects are represented by increased amount of Mn-SOD protein. A 
clinical study showed that physical exercise weakens apoptosis in skeletal muscle, improves antioxidant capacity, and decreases oxidative stress, which may reduce apoptosis genes. Physical activity apparently reduces the amount of apoptosis (6).

\section{Conclusion}

Our findings showed that 8-week curcumin consumption along with training significantly

\section{Acknowledgements}

This article is extracted from a doctoral thesis on sports physiology, cardiovascular branch, which was registered in the Physiology Department of Islamic Azad University, Tehran Branch, under the code No. 10121404961004. The present study received the Ethics Code 77/614 / F from the Medical Ethics Committee of the Azad University, Sari Branch. The authors would like to thank and appreciate the vice president of research at the Islamic Azad University, Sari Branch,

\section{References}

1.Kwak HB. Effects of Aging and exercise training on apoptosis in the heart, $\mathrm{J}$ of exer rehab, 2013, 9(2):212-219

2. Nitahara JA, Cheng W, Liu Y, Li B, Leri A, Li P, Mogul D, Gambert SR, Kajstura J, Anversa P. intracellular calcume, DNase activity and myocyte apoptosis in aging ficsher 344 rats. J MOL CELL CARDIOL ,1998, 30(3):519-535.

3. Silva AC, de Almeida BF, Soeiro CS, Ferreira WL, de Lima VM, Ciarlini PC. Oxidative stress, superoxide production, and apoptosis of neutrophils in dogs with chronic kidney disease. Can J Vet Res. 2013 Apr;77(2):136-41

4. Maiorana A . Interval training confers greater gains than continuous training in people with heart failure. J Physiother. 2012;58(3):199. (12)70113-3. reduced apoptosis ratios, thereby increasing the apoptosis $\mathrm{Bcl} 2$ expression and reducing the expression of $\mathrm{BAX}$ and $\mathrm{BAX} / \mathrm{Bcl} 2$ ratios. We also documented that moderate intensity training reduced apoptosis in mice.

The findings of this study highlight the effect of training and curcumin consumption on reducing apoptosis and can be used to maintain heart health in aging and promote cardiac rehab.

and the authorities of the Sports Physiology Laboratory at this University for their sincere contribution in this study.

\section{Declarations}

\section{Conflict of interest}

We declare that we have no financial or non-financial conflicts of interest related to the subject matter or materials discussed in the article.

\section{Authors' contributions}

All authors contributed equally to this work.

5. Chen TI, Shen YJ, Wang IC, Yang KT. Short term exercise provides left ventricular myocardial protection against intermittent hypoxia-induce apoptosis in rats , Eur J Appl Physiol. 2011 Aug;111(8):1939-50.

6. Garza MA, Wason EA, Zhang JQ. Cardiac remodeling and physical training post myocardial infarction. World J Cardiol. 2015 Feb 26;7(2):5264

7. Jiang S, Han J, Li T, Xin Z, Ma Z, Di W, Hu W, Gong B, Di S, Wang D, Yang Y. Curcumin as a potential protective compound against cardiac diseases. Pharmacol Res. 2017 May;119:373383.

8. GBD 2013 Mortality and Causes of Death Collaborators. Global, regional and national age sex specific all-cause and cause - specific 
mortality for 240 causes of death. Lancet. 2015 Jan 10;385(9963):117-71.

9. Huang WC, Chiu WC, Chuang HL, Tang DW, Lee ZM, Wei L, Chen FA, Huang CC. Effect of curcumin supplementation on physiological fatigue and physical performance in mice. Nutrients. 2015 Jan 30;7(2):905-2.

10. Sugawara J, Akazawa N, Miyaki A, Choi Y, Tanabe Y, Imai T, Maeda S. Effect of endurance exercise training and curcumin intake on central arterial hemodynamics in postmenpausal women: pilot study. Am J Hypertens. 2012 Jun;25(6):6516.

11. Akazawa N, Choi Y, Miyaki A, Tanabe Y, Sugawara J, Ajisaka R. Effects of curcumin intake and aerobic exercise training on arterial compliance in postmenopausal women. Journal of artery .2013, 7(1): 67-72.

12. Sofi F, Capalbo A, Cesari F, Abbate R, Gensini GF. Physical activity during leisure time and primary prevention of coronary heart disease : an updated mata analysis of cohort studies. Eur $\mathbf{J}$ Cardiovasc Prev Rehabil. 2008 Jun;15(3):247-57.

13. Lenk K, Uhlemann M, Schuler G, Adams V. Role of endothelial progenitor cells in the beneficial effects of physical activity on atherosclerosis and coronary aetery disease. J Appl physiol.2012, 111(1):321-8.

14. Waring CD, Vicinanza C, Papalamprou A, Smith AJ, Purushothaman S, Goldspink DF, Nadal-Ginard B, Torella D, Ellison GM. The adult heart responds to increased workload with physiologic hypertrophy, cardiac stem cell activation and new myocyte formation. Eur Heart J. 2014 Oct 14;35(39):2722-31

15. Ames BN, Shiganaga MK, Hagen $T$. Oxidants, antioxidants and degenerative diseases of aging. Proc Natl Acad Sci.1993, 90(17):79157922.

16. Liu H, Wang C, Qiao Z, Xu Y. Protective effect of curcumin against myocardium injury in ischemia reperfusion rats. Pharm Biol. 2017 Dec;55(1):1144-1148.

17. Lee SD, Shyu WC, Cheng IS, Kuo CH, Chan YS, Lin YM, Tasi CY, Tsai CH, Ho TJ, Huang CY. Effects of exercise training on cardiac apoptosis in obese rats. Nutr Metab Cardiovasc Dis. 2013 Jun;23(6):566-73 .

18. Peterson JM, Bryner RW, Sindler A, Frisbee JC, Always SE. Mitochondrial apoptotic signaling is elevated in cardiac but not skeletal muscle in the obese Zucker rat and is reduced with aerobic exercise . J Appl physiol . 2008,105:1934-43.

19. Cory S, Huang DC, Adams JM. The Bcl2 family: roles in cell survival and oncogenesis. Oncogene. 2003 Nov 24;22(53):8590-607.

20. Powers SK, Lennon SL, Quindry J, Mehta JL. Exercise and cardioprotection. Curr opin cardiol. 2002,17(5):495-502.

21. Pinheiro AR, Cunha AR, Aguila MB, Mandarim-de-Lacerda CA. Beneficial effects of physical exercise on hypertension and cardiovascular adverse remodeling of dietinduced obese rats. Nutr Metab Cardiovasc Dis. 2007 Jun;17(5):365-75.

22. Phaneuf S, Leeuwenburgh C. Cytochrome C release from mitochondrial in the aging heart: a possible mechanism for apoptosis with age. Am J Physiol Regul Integr Comp Physiol. 2002 Feb;282(2):R423-30.

23. Gyu K II, Sung EK, Chang JK, Yong SJ. Treadmill exercise alleviates aging-induced apoptosis in rat cardiac myocytes. International journal of gerontology.2013, 7(3): 152-7.

24. Zhang D, Mott JL, Chang SW, Denniger G, Feng Z, Zassenhaus HP. Construction of transgenic mice with tissue specific acceleration of mitochondrial DNA mutagenesis . Genomics. 2000 Oct 15;69(2):151-61.

25. M Chiong, Z V Wang, Z Pedrozo, D J Cao, R Troncoso, M Ibacache, A Criollo, A Nemchenko, J A Hill, and S Lavandero.Cardiomyocyte death mechanisms and translational implications. Cell Death Dis. 2011 Dec; 2(12): e244.

26 Geng HH, Li R, Su YM, Xiao J, Pan M, Cai $\mathrm{XX}$, Ji XP. Curcumin protects cardiac myocyte against hypoxia - induced apoptosis through upregulating $\mathrm{miR}-7 \mathrm{a} / \mathrm{b}$ expression. Biomed Pharmacother. 2016 Jul;81:258-264.

27 Esatbeyoglu T, Huebbe P, Ernst IM, Chin D, Wagner AE, Rimbach G. Curcumin trom 
molecule to biological function. Angew Chem Int Ed Engl. 2012 May 29;51(22):5308-32.

28 Naksuriya O, Okonogi S, Schiffelers RM, Hennink WE. Curcumin nanoformulations : a review of pharmaceutical properties and preclinical studies and clinical data related to cancer treatment. Biomaterials. 2014 Mar;35(10):3365-83.

29. Castro CN, Barcala Tabarrozzi AE, Winnewisser J, Gimeno ML, Antunica Noguerol M, Liberman AC, Paz DA, Dewey RA, Perone MJ. Curcumin ameliorates autoimmune diabetes : Evidence in accelerated morine modies of type 1 diabets. Clin exp immunal. 177(1): 149-160.

30 Wongcharoen $\mathrm{W}$, Phrommintikul A. The protective role of curcumin in cardiovasculare diseases. Int J Cardiol. 2009 Apr 3;133(2):145-51.

31 Morimoto T, Sunagawa Y, Kawamura T, Takaya T, Wada H, Nagasawa A, Komeda M, Fujita M, Shimatsu A, Kita T, Hasegawa K. The dietary compound curcumin inhibits p300 instone acetyltransferase activity and prevents heart failure in rats . J Clin Invest. 2008 Mar;118(3):868-78.

32. Meng Z, Yu XH, Chen J, Li L, Li S. Curcumin attenuares cardiac fibrosis in spontaneously hypertentensive rats through PPAR- $\vee$ activation . Acta Pharmacol Sin. 2014 Oct;35(10):1247-56.

33 Wang NP, Wang ZF, Tootle S, Philip T, Zhao ZQ. Curcumin promotes cardiac repan and ameliorates cardiac dysfunction following myocardial infraction. $\mathrm{Br} \mathrm{j}$ pharmacol. 2012,167(7): 1550-1562.

34. Zhang Y, Chong E, Herman B, Aging associated increases in the activity of multiple caspase in fisher 344 rat organs. Exp Geront 2002, 37: 777-789.

35. Hoshino D, Kitaoka Y, Hatta H. High intensity interval training increase intrinsic rates of mitochondrial fatty acid oxidation in rat red and white skeletal muscle . 2013. Appl Physio Nutr Metab 38:326-333.

\section{How to cite:}

Chaharmahali Y B, Azarbayjani M A, Peeri M, Farzanegi Arkhazloo P. Increased Expression of Bax and Bcl2 Apoptosis Biomarkers in the Heart of Old Female Rats after Interval Training and Curcumin Consumption. Jorjani Biomedicine Journal. 2018; 6(4): 40-52. 